\title{
Circulating antibodies to corneal epithelium in patients with uveitis
}

\author{
PIET JAN KRUIT, ${ }^{2}$ RUTH VAN DER GAAG, ${ }^{2}$ LIDY BROERSMA, ${ }^{2}$ AND \\ AIZE KIJLSTRA ${ }^{2}$
}

From the 'Department of Ophthalmology, Free University of Amsterdam, and the ${ }^{2}$ Department of OphthalmoImmunology, The Netherlands Ophthalmic Research Institute, Amsterdam

SUMMARY We investigated the incidence of circulating corneal epithelium antibodies in patients with uveitis. A high percentage of the patients (42\%) were positive, whereas only $4 \%$ of controls had these antibodies in their serum. Significantly more patients with anterior and diffuse uveitis had corneal epithelium antibodies than did those with posterior uveitis. Subdivision of anterior uveitis into HLA-B27 positive versus negative patients showed a higher incidence of the antibodies in the HLA-B27 positive group. A previous history of uveitis may play a role in the pathogenesis of peripheral corneal thinning diseases, for which an autoimmune aetiology has been suggested.

The peripheral corneal thinning syndrome includes many corneal ulcerative diseases such as Mooren's ulcer, Wegener's granulomatosis, polyarteritis nodosa, Terrien's disease, and rheumatoid arthritis. Many possible causes for this syndrome have been proposed, but as yet none have been proved. A recent study' showed that circulating immune complexes may play a role in the pathogenesis of Mooren's ulcer and marginal ulceration in the presence of collagen vascular disease. However, earlier studies suggested a humoral autoimmune response against corneal antigens as a pathogenetic mechanism of the Mooren's ulcer. ${ }^{2-4}$ In 1969 Schaap et al. ${ }^{2}$ were the first to show the presence of circulating antibodies to corneal epithelium in a patient with Mooren's ulcer. This finding was confirmed by Brown and Mondino ${ }^{34}$ and other workers. ${ }^{56}$ In a recent study from our institute Van der Gaag et al. ${ }^{7}$ found a high incidence of circulating corneal epithelium antibodies $(81 \%)$ in African patients with a Mooren's ulcer. A local control group, however, also had a high prevalence $(87 \%)$ of these antibodies.

These findings raised the question whether the presence of circulating antibodies to corneal epithelium is the primary cause of the ulceration or whether these antibodies reflect a secondary phenomenon following a generalised parasitic or viral infection. ${ }^{8}$ Another hypothesis may be that these

Correspondence to P J Kruit, MD, The Netherlands Ophthalmic Research Institute, Department of Ophthalmo-Immunology, PO Box 12141, 1100 AC Amsterdam, The Netherlands. antibodies are elicited by previous ocular inflammation. Evidence for the latter theory was obtained in the investigation reported here, studying the incidence of circulating corneal epithelium antibodies in uveitis patients. Our study shows that approximately $40 \%$ of the patients with uveitis have circulating corneal epithelium antibodies compared with $4 \%$ in a control group.

\section{Materials and methods}

Sera were obtained during an attack of uveitis from 133 patients visiting the university eye clinics of Rotterdam (Dr Baarsma), the Amsterdam Academic Hospital of the Free University (Dr Tjoa), and the Academic Medical Centre (Dr Rothova), and from 70 control persons attending the outpatient department for refraction only and staff members. All controls were questioned about previous ocular inflammation and examined with the slit-lamp for corneal defects. Patients and controls were comparable as to age and sex (patients 68 males, 65 females, average age 35 years; control group 23 males, 29 females, average age 33 years).

The uveitis patients were classified as having anterior $(n=84)$, posterior $(n=33)$, or diffuse uveitis $(n=16)$. Most patients underwent routine blood screening (erythrocyte sedimentation rate, haemoglobin level, white blood cell count). We also tested immunoglobulin levels (IgG, IgM, IgA, IgE, and IgD), complement levels ( $\mathrm{C} 3, \mathrm{C} 4, \mathrm{Clq}, \mathrm{CH} 50)$, 
circulating immune complex levels, autoantibodies (rheumatoid factor, anti-DNA, antinuclear antibody, anti-smooth muscle, anti-parietal cells, antimitochondria), syphilis serology, toxoplasma serology, serum angiotensin-converting enzyme and lysozyme levels, and carried out HLA-B27 typing; in the case of patients with birdshot retinopathy HLAA29 typing was performed. Most of the HLA-B27 positive patients with anterior uveitis were examined by a rheumatologist for ankylosing spondylitis.

Circulating antibodies against corneal epithelium were assayed by an indirect immunofluorescence technique on rabbit corneas. The corneas were frozen in liquid nitrogen and $4 \mu \mathrm{m}$ sections were cut in a cryostat. The sections were air dried on slides, overlaid with a $1 / 10$ serum dilution in phosphate buffered saline (PBS), and incubated for 30 minutes at room temperature. The slides were subsequently washed with PBS at $37^{\circ} \mathrm{C}$ and incubated for 30 minutes in the dark at room temperature, with a fluorescein labelled goat anti-human immunoglobulin (Nordic) diluted 1/40 in PBS.

The slides were washed thoroughly and covered with a solution of $90 \%$ glycerin and $10 \%$ PBS containing $100 \mathrm{mg}$ P-phenylenediamine to prevent fluorescence fading. ${ }^{9}$ They were scored double blind (that is, by two separate investigators unaware of the patient's serum used) with a fluorescence microscope equipped with epi-illumination. Statistical analysis of the data was performed by the $\chi^{2}$ test.

\section{Results}

Circulating corneal epithelium antibodies - were found in a high percentage (42\%) of the uveitis patients, whereas these antibodies occurred in only $4 \%$ of the control series $(p<0.005)$. Two out of 52 control persons had circulating corneal epithelium antibodies (Table 1). One wore contact lenses; the other had a nebula corneae in one eye and a previous history of a foreign body in the same eye.

In the immunofluorescence technique rabbit corneas were used as a substrate. Extensive studies comparing human corneas (blood group $\mathrm{O}$ ) with rabbit corneas as a substrate showed no differences in the results (Table 2). Incubation of positive sera with rabbit erythrocytes and lymphocytes did not show any absorbtion of the circulating corneal epithelium antibodies. These sera, positive for corneal epithelium, were specific for the cornea and did not react with other tissues, such as conjunctival epithelium, lens epithelium, oesophagus epithelium, or mucosa of the cavia lip. Only one serum reacted weakly with smooth muscle, whereas none reacted with parietal cells and thyroid.

Subdivision of the anterior uveitis group into
Table 1 Antibodies to corneal epithelium in uveitis patients and controls

\begin{tabular}{lrr}
\hline Group & $\begin{array}{l}\text { Number of } \\
\text { patients }\end{array}$ & $\begin{array}{l}\text { \% Positive for corneal } \\
\text { epithelium antibodies }\end{array}$ \\
\hline Anterior uveitis & & \\
HLA-B27 positive & 35 & 54 \\
HLA-B27 negative & 49 & 30 \\
Total & 84 & 42 \\
Posterior uveitis & & \\
Behçet's disease & 3 & 30 \\
Toxoplasmosis & 6 & 17 \\
Sarcoidosis & 1 & 0 \\
Birdshot retinopathy & 3 & 0 \\
Multiple sclerosis & 1 & 0 \\
Pars planitis & 1 & 0 \\
Tuberculosis & 2 & 50 \\
Unknown aetiology & 16 & 44 \\
Total & 33 & 30 \\
Diffuse uveitis & & \\
Sarcoidosis & 4 & 75 \\
Syphilitic infection & 2 & 100 \\
Behçet's disease & 1 & 100 \\
Ankylosing spondylitis & 2 & 0 \\
Unknown & 7 & 57 \\
Total & 16 & 69 \\
All uveitis patients & 133 & 42 \\
Control population & 52 & 4 \\
\hline
\end{tabular}

HLA-B27 positive and negative showed that the incidence of corneal epithelium antibodies was significantly $(p<0.02)$ higher in the HLA-B27 positive group. The presence or absence of ankylosing spondylitis in the HLA-B27 positive patients did not correlate with the presence of corneal epithelium antibodies. The patients with anterior and diffuse uveitis had a higher incidence of corneal epithelium antibodies than did those with posterior uveitis $(p<0 \cdot 005)$. No correlation was found between the presence of corneal epithelium antibodies and other immunological parameters studied, such as immunoglobulin levels, complement levels, circulating immune complexes, and other autoantibodies tested.

Table 2 Comparison of rabbit cornea and human cornea (blood group O) used as a substrate to determine corneal epithelium antibodies

\begin{tabular}{|c|c|c|}
\hline & Rabbit cornea & Human cornea \\
\hline \multicolumn{3}{|l|}{ Positive sera } \\
\hline 1 & + & + \\
\hline 2 & + & + \\
\hline 3 & ++ & ++ \\
\hline 4 & + & + \\
\hline 5 & + & $(+)$ \\
\hline Negative sera & & \\
\hline 1 & - & - \\
\hline 2 & - & - \\
\hline \multicolumn{3}{|l|}{$\begin{array}{l}++=\text { Strong positive. } \\
+=\text { Positive. } \\
(+)=\text { Weak positive. }\end{array}$} \\
\hline
\end{tabular}


No influence was found of sex and age on the occurrence of corneal epithelium antibodies.

\section{Discussion}

Our results show a high occurrence of corneal epithelium antibodies in uveitis patients $(42 \%)$ as compared with a control group (4\%). Cell mediated immune reactions against corneal antigens have been described earlier in uveitis patients..$^{1011}$ One study 11 reported that no antibodies could be found against corneal antigens by the Ouchterlony immunodiffusion technique. The immunofluorescence technique used in our study is, however, known to be more sensitive.

The pathogenesis of the peripheral corneal thinning diseases remains speculative. An immune complex mediated disease has been implicated in Wegener's granulomatosis, polyarteritis nodosa, and rheumatoid arthritis. ${ }^{12} 13$

The aetiology of Mooren's ulcer and Terrien's disease is undetermined, though an autoimmune mechanism has been proposed. Several investigators have demonstrated the presence of circulating antibodies in these patients. ${ }^{2-6}$ In addition both immunoglobulin and complement deposits have been demonstrated in conjunctivae and corneal biopsies. ${ }^{34}$

A recent study' showed a high frequency of corneal epithelium antibodies ( $81 \%$ positive) in African patients with Mooren's ulcer. The same frequency $(87 \%)$ was also found in local controls. The frequent occurrence of both Mooren's ulcer and circulating corneal epithelium antibodies in Africans compared with the rarity of Mooren's ulcer and the low incidence of corneal epithelium antibodies in Europeans would indirectly suggest that these autoantibodies have a part in the pathogenesis of the disease.

A history of a previous uveitis is present in a number of peripheral thinning diseases. ${ }^{14}$ Corneal disorders are frequently seen in association with iridocyclitis. Some of these entities are probably caused by a viral infection of both the cornea and the uvea. On the other hand it may be that autoimmunity against the cornea is developed during the uveitis, leading to a keratouveitis. Investigation of selected patients with keratouveitis may clarify this issue.

The increased congestion and permeability of the vessels in the anterior segment may be an important prerequisite for the induction of corneal epithelium antibodies. In the case of a diffuse uveitis and anterior uveitis vascular permeability is increased, leading to a greater accessibility of the corneal epithelium antigens to the immune system, which may result in the active production of antibodies to these antigens. If these circulating corneal epithelium antibodies gain access to the corneal epithelium as a result of corneal inflammation or trauma, immune complexes are formed locally. These complexes may activate the complement system, promoting chemotaxis of inflammatory cells, finally resulting in serious damage to the corneal tissue.

We are now investigating the role of circulating corneal epithelium antibodies in the pathogenesis of corneal thinning diseases using an animal model.

\section{References}

1 Berkowitz PJ, Arentsen JJ, Felberg NT, Laibson PR. Presence of circulating immune complexes in patients with peripheral corneal disease. Arch Ophthalmol 1983; 101: 242-6.

2 Schaap OL, Feltkamp TEW, Breebaart AC. Circulating antibodies to corneal tissue in a patient suffering from Mooren's ulcer (ulcus rodens corneae). Clin Exp Immunol 1965; 5: 365-70.

3 Mondino BJ, Brown SI, Rabin BS. Autoimmune phenomena of the external eye. Ophthalmology 1978; 85: 801-17.

4 Brown SI, Mondino BJ, Rabin BS. Autoimmune phenomenon in Mooren's ulcer. Am J Ophthalmol 1976; 82: 835-40.

5 Pau H, Smitt-Graft A. Das Ulcus Rodens Mooren als mögliche autoaggressions Krankheit. Klin Monatsbl Augenheilkd 1983; 183: $192-4$.

6 Murray PI, Rahi AHS. Pathogenesis of Mooren's ulcer: some new concepts. Br J Ophthalmol 1984; 68: 182-7.

7 Gaag R van der, Abdillahi A, Stilma JS, Vetter JCM. Circulating antibodies against corneal epithelium and hookworm in patients with Mooren's ulcer from Sierra Leone. Br J Ophthalmol 1983; 67: 623-8.

8 Haspel MV, Onodera T, Prabhaka BS, Horita M, Suzuki H, Notkins AL. Virus-induced auto-immunity: monoclonal antibodies that react with endocrine tissues. Science 1983; 220: 304-6.

9 Johnson GD, Gloria M, Arajo CN. A simple method of reducing the fading of immunofluorescence during microscopy. J Immunol Methods 1981; 43: 349-50.

10 Feinberg BE, Shore B, Leopold IH, Henley WL. Cellular immunity in chronic ophthalmic disorders. Am J Ophthalmol 1972; 73: 68-73.

11 Basu PK, McCulloch C. The presence of cell mediated immunity in uveitis. Can J Ophthalmol 1977; 12: 133-9.

12 Smolin G, O'Connor GR. Introduction to immunology: special ocular considerations. In: Smolin G, O'Connor GR, eds. Ocular immunology. Philadelphia: Lea and Febiger, 1981: 59-68.

13 Rahi AHS, Garner A. Immunopathology of the eye. Oxford: Blackwell, 1976: 131.

14 Smolin G, Thoft RA. The cornea, scientific foundations and clinical practice. In: Smolin G, Thoft RA, eds. Boston, Toronto: Little, Brown, 1983: 231-92. 